\title{
NOTES ON TERMS
}

\section{JAPANESE NAMES AND WORDS}

Names of Japanese people are given in the Japanese order (family name first), except in bibliographic citations for English-language works in which they were originally listed in the Western order. Japanese names, especially the personal names of public figures, often have alternate readings. For example, Prime Minister Hara Takashi is also called Hara Kei. In such cases, following the practice of most Japanese biographical dictionaries, I use the standard Japanese-style version of the name. I do include the alternate Chinese-style (on) reading on first introduction and in the index. Many Japanese family names, such as Takahashi and Inoue, are very common, and no family relationship should be assumed between bearers of the same family name. Speakers of Japanese will find it unnecessary, but to clarify names (following the example of Marshall Hodgson in his Venture of Islam, I frequently add redundant English identifiers. For example, "Minseitō party," even though the element $t \bar{o}$ itself means party. When rendered into the Latin alphabet, Japanese words are pronounced more or less as they would be in Spanish or Italian.

\section{MONEY}

The symbol ¥ in the text means Japanese yen; \$ means U.S. dollars; £ means British pounds. Billion means 1, ooo million. Under the system of par values prevailing from 1897 to 1931 , a conventional rule of thumb in Japan was to reckon $£_{1}=¥ 10$ and $\$ 1=¥ 2$. In expressing currency equivalences, I also follow that convention here. Under the former British system, one pound (£) $=20$ shillings $(s$.$) , and 1$ shilling $=12$ pence $(d$.$) .$ 


\section{DATES}

Dates in citations are given in month/day/year format. Modern Japanese era names (which since 1868 have been imperial reign names) are as follows:

$\begin{array}{ll}\text { Meiji } & 1868-1912 \\ \text { Taisho } & 1912-26 \\ \text { Showa } & 1926-89 \\ \text { Heisei } & 1989-\end{array}$

\section{ABBREVIATIONS}

For abbreviations used in the citations, please see the bibliography.

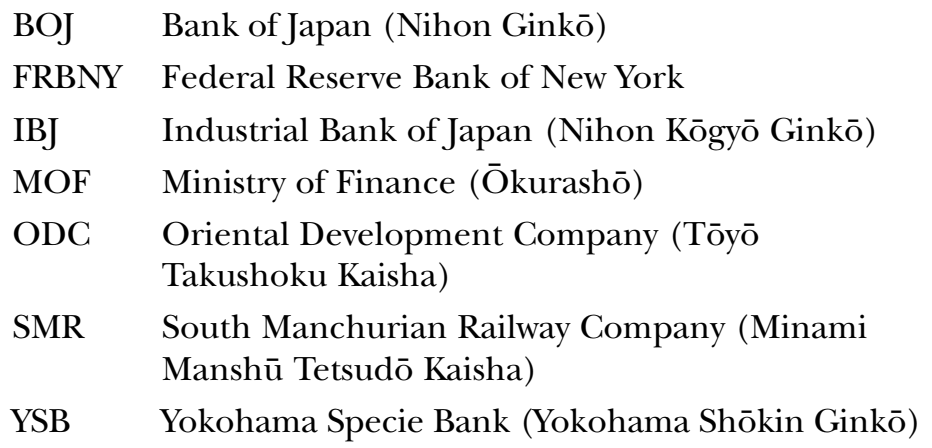

\section{ROMANIZATION OF CHINESE NAMES}

Except for a few names that are very well known in other forms (e.g., Kwantung Army, Chiang Kai-shek, Mukden,) Chinese names are rendered in their Mandarin forms using pinyin romanization. Alternative romanizations in the Wade-Giles system can be found in the index listings. 


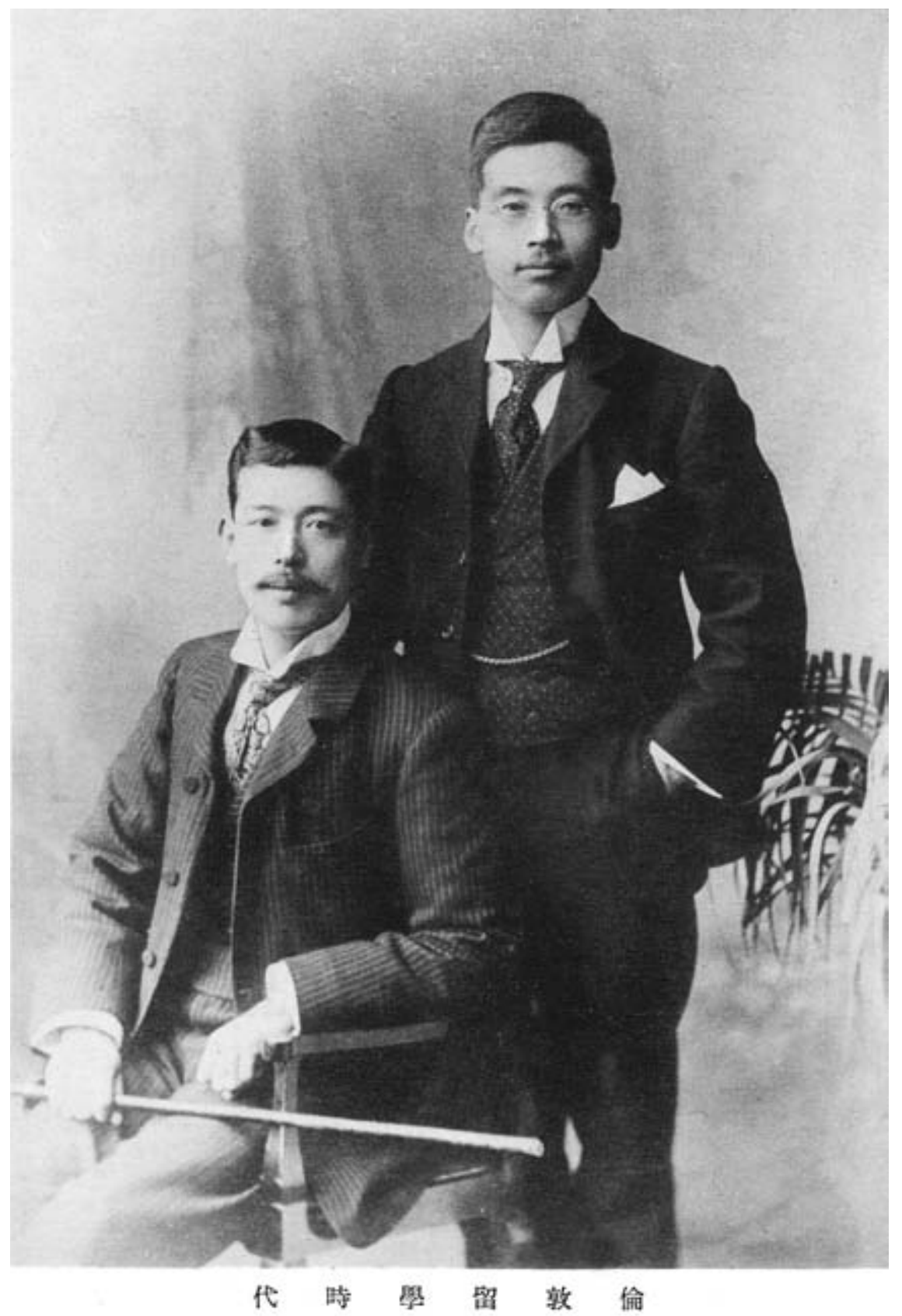

Plate 1. Inoue Junnosuke (standing) and Hijikata Hisaakira as trainees in London, 1897 or 1898 . From IJD. 


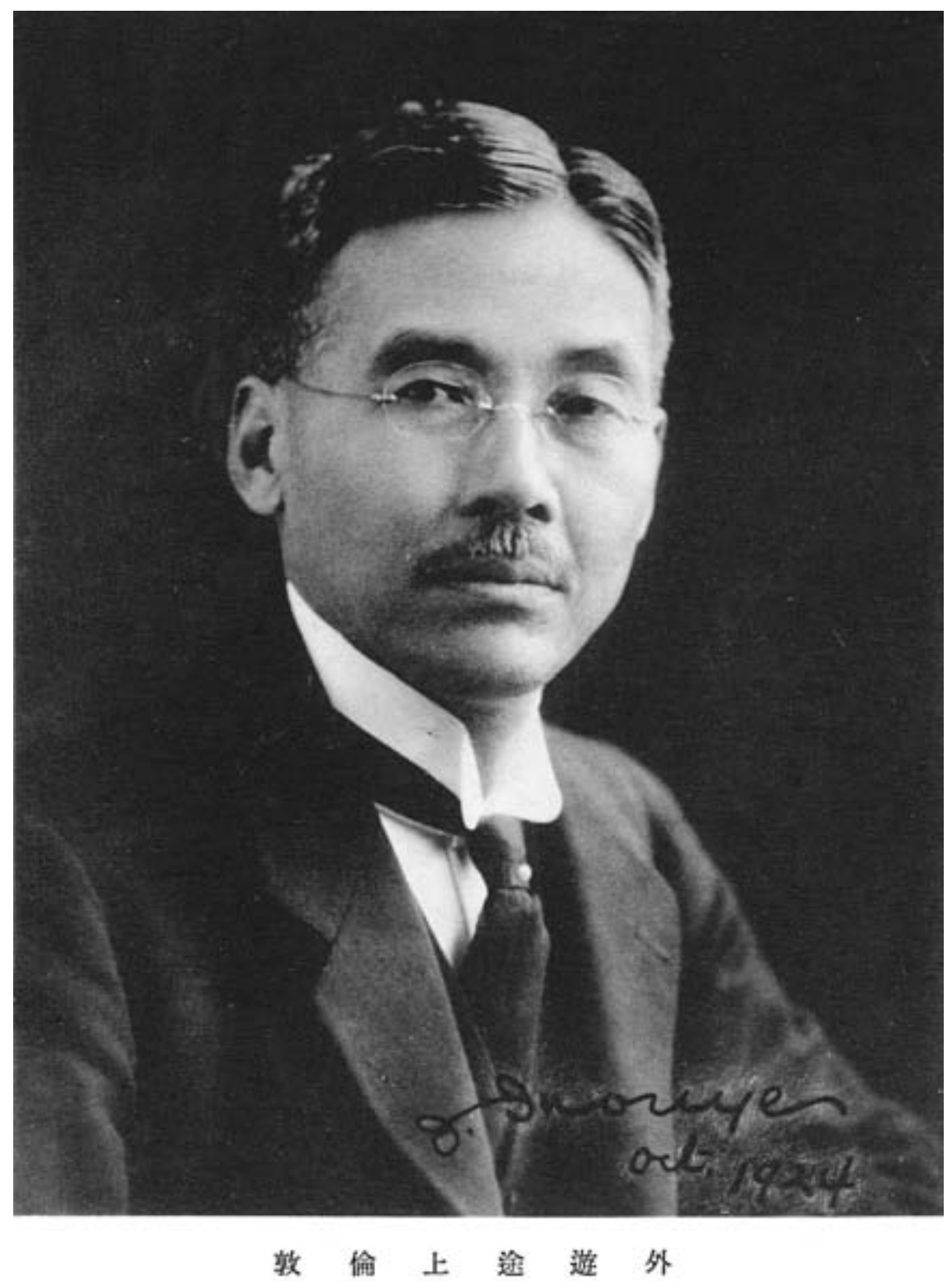

Plate 2. Inoue Junnosuke at the time of his trip to London, 1924. From IJD. 